\title{
Efeito do lipopolissacarídeo de Escherichia coli sobre a proliferação de osteoblastos
}

\section{Effect of Escherichia coli lipopolisacaride on proliferation of osteoblasts}

\author{
Victor Perez Teixeirali; Raquel Agnelli Mesquita Ferrari2; Sandra Kalil Bussadori3; Marcelo Betti \\ Mascaro ; Kristianne Porta Santos Fernandes 5 \\ Mestrando do Programa de Ciências da Reabilitação - Uninove. São Paulo, SP - Brasil. \\ 2Doutora em Ciências Fisiológicas - UFSCar, Professora do curso de Mestrado em Ciências da Reabilitação - Uninove. \\ São Paulo, SP - Brasil. \\ ${ }^{3}$ Doutora em Ciências Odontológicas - USP, Professora do curso de Mestrado em Ciências da Reabilitação - Uninove. \\ São Paulo, SP - Brasil. \\ ${ }^{4}$ Doutor em Anatomia (ICB/USP), Professor do Curso de Odontologia - Uninove. São Paulo, SP - Brasil \\ ${ }^{5}$ Doutora em Imunologia (ICB/USP), Professora do curso de Mestrado em Ciências da Reabilitação - Uninove. \\ São Paulo, SP - Brasil. \\ Endereço para correspondência \\ Kristianne Porta Santos Fernandes - Uninove/Departamento \\ de Ciências da Reabilitação \\ Av. Francisco Matarazzo, 612 \\ 05001-100 - São Paulo - SP [Brasil] \\ victorpteixeira@hotmail.com
}

Resumo

Introdução: O lipolissacarídeo (LPS) é um componente majoritário da parede celular de bactérias gram-negativas, reconhecido como potente indutor de resposta inflamatória e de reabsorção óssea. Objetivo: Investigar o efeito do LPS de Escherichia coli, sobre a proliferação de osteoblastos. Métodos: Os osteoblastos foram cultivados com diferentes concentrações de LPS $(0,1,1$ e $10 \mu \mathrm{\mu g} / \mathrm{ml})$ e as culturas do grupo controle não receberam a adição desse composto. A análise da proliferação celular foi realizada por meio do teste MTT. Resultados: A adição de LPS, na concentração de $1 \mu \mathrm{g} / \mathrm{ml}$, diminuiu a proliferação celular (porém de maneira estatisticamente não significante), quando comparado com as células do grupo controle e demais grupos. Conclusão: Esse resultado sugere que a proliferação de osteoblastos pode ser afetada pelo LPS de Escherichia coli e, sendo assim, poderia ter um papel importante nos quadros de destruição óssea por infecção de bactérias gram-negativas.

Descritores: Reabsorção óssea; Osteoblastos; LPS.

\begin{abstract}
Introduction: LPS is the major component of the gram-negative bacterial cell wall. It is traditionally recognized as an endotoxin which induces a strong response from normal animal immune systems and bone loss. Objective: In this study, we investigated the effect of LPS, extracted of Escherichia coli, on the proliferation of osteoblasts. Methods: The osteoblasts were cultured with different concentration of LPS $(0.1,1$ and $10 \mu \mathrm{g} / \mathrm{ml})$. Untreated cultures were used as controls. The analysis of the cellular proliferation was performed using the MTT method. Results: The results revealed a non-significant decrease in the proliferation of osteoblasts treated with $1 \mu \mathrm{g} / \mathrm{ml}$ of LPS. Conclusion: LPS of Escherichia coli may promote a decrease in osteoblasts proliferation and play an important role in cases of bone loss after gram-negative infection.
\end{abstract}

Key words: Bone resorption; Osteoblasts; LPS. 


\section{Introdução}

O tecido ósseo é um tecido conjuntivo especializado que, em conjunto com o tecido cartilaginoso, forma o sistema esquelético. Os tipos celulares específicos desse tecido são os osteoblastos, os osteócitos e os osteoclastos. Os osteoblastos têm como função primordial a formação de osso, e nesse processo formativo acabam por ficar aprisionados em seu próprio produto secretório (matriz mineralizada), sendo progressivamente diferenciados em osteócitos ${ }^{1}$. Já os osteoclastos são essenciais no processo de remodelamento por serem responsáveis pela reabsorção óssea ${ }^{2,3}$.

O metabolismo ósseo é um processo contínuo e dinâmico de reabsorção e de deposição óssea regulado localmente por redes de hormônios, citocinas e outros fatores. Em situações patológicas, que incluem a osteoporose, a artrite reumatoide, a osteoartrite e infecções ósseas, citocinas e mediadores locais são responsáveis pelo aumento da reabsorção osteoclástica e pela inibição da reparação nos locais onde houve perda óssea ${ }^{4}$.

Bactérias e seus produtos causam perda óssea inflamatória em um grande número de condições, incluindo otite crônica média, periodontite, lesões endodônticas, perda de implantes ortopédicos etc. ${ }^{5}$. Entretanto, ainda não está suficientemente claro como elas provocam essa perda óssea, existindo três possibilidades: ou as bactérias destroem diretamente os componentes ósseos por liberação de ácidos e proteases; ou elas acarretam processos celulares que estimulam a degradação óssea; ou inibem a síntese de matriz óssea ${ }^{6}$.

O lipopolissacarídeo (LPS), componente da parede de bactérias gram-negativas, foi o primeiro elemento bacteriano cuja capacidade de induzir reabsorção óssea já foi demonstrada7 ${ }^{7}$.

Várias evidências têm estabelecido o conceito de que o LPS estimula os osteoblastos e outras células a secretarem vários fatores promotores de reabsorção óssea como a prostaglandina E2 (PGE2) e as citocinas: fator de necrose tumoral $\alpha$ (TNF- $\alpha$ ) e a interleucina 1 (IL-1) nos tecidos inflamados $6,8,9,10,11$.

Entretanto, os mecanismos de ação envolvidos nesse processo não estão totalmente elucidados. Especificamente, não está claro se o LPS aumenta a osteoclastogênese diretamente tendo como alvo os precursores de osteoclastos ou indiretamente por meio de células intermediárias como os osteoblastos ${ }^{5,12}$. Devido à grande prevalência na população em situações de perdas ósseas por infecção bacteriana, é fundamental compreendermos o processo pelo qual essa infecção produz reabsorção óssea, até mesmo para condução de terapias mais eficazes. Desse modo, neste artigo, propõe-se avaliar o efeito do lipolissacarideo de Escherichia coli sobre a proliferação de osteoblastos.

\section{Material e métodos}

Este estudo foi conduzido no laboratório de cultivo celular do curso de Mestrado em Ciências da Reabilitação da Universidade Nove de Julho (Uninove). As células utilizadas foram osteoblastos da linhagem OSTEO-1 ${ }^{13}$, gentilmente doadas pela professora Márcia Martins Marques, da Faculdade de Odontologia da Universidade de São Paulo USP/SP.

A linhagem foi cultivada no meio de cultura de Eagle modificado por Dulbecco (DMEMVitrocell, Campinas, SP, Brasil), contendo 10\% de soro fetal bovino (FBS) (Cultilab, Campinas, SP, Brasil). As culturas foram mantidas em estufa (HEPA class 3110, Thermo Electron Corporation, Marietta, $\mathrm{OH}, \mathrm{EUA})$ a $37{ }^{\circ} \mathrm{C}$, numa atmosfera úmida contendo $5 \%$ de $\mathrm{CO}_{2}$. O monitoramento do crescimento celular foi realizado a cada 24 horas, utilizando-se microscópio invertido de fase (Eclipse TE 2000U, Nikon, Melville, NY, EUA). O subcultivo foi realizado quando a monocamada celular tornou-se subconfluente, objetivando a perpetuação da linhagem celular, sempre em fluxo laminar (Linha 400, Pachane, Piracicaba, SP, Brasil). Para tanto, o sobrenadante foi removido, as células lavadas com tampão PBS1X 
( $\mathrm{NaCl} 140 \mathrm{mM} ; \mathrm{KCl}$ 2,5mM; $\mathrm{Na}_{2} \mathrm{HPO}_{4} 8 \mathrm{mM}$; $\mathrm{KH}_{2} \mathrm{PO}_{4} 1,4 \mathrm{mM} ; \mathrm{pH}$ 7.4) e tratadas com solução de tripsina $0,25 \%$, durante três minutos, a $37^{\circ} \mathrm{C}$. Após incubação foi realizada nova lavagem com meio, centrifugação a $1.200 \mathrm{rpm}$, a $20^{\circ} \mathrm{C}$, por cinco minutos (Centrífuga Excelsa 4-280R, Fanem, São Paulo, SP, Brasil) e, posteriormente, ressuspensão em $1 \mathrm{ml}$ de meio DMEM. A viabilidade das células foi avaliada por contagem com corante vital azul de Trypan (0,4\%), e utilizadas, nos ensaios, as culturas com viabilidade maior que $95 \%$.

\section{Ensaio de proliferação celular (método MTT)}

A metodologia se baseia na habilidade da enzima mitocondrial desidrogenase, encontrada somente em células viáveis, em clivar os anéis de tetrazólio do MTT, formando cristais azuis escuros de formazana, os quais são impermeáveis às membranas celulares, ficando então retidos no interior das células viáveis ${ }^{14,15}$. A posterior lise celular faz com que esses sais de formazana sejam liberados. O número de células viáveis é diretamente proporcional ao nível desses cristais produzidos.

Para avaliar o efeito do LPS sobre as linhagens celulares, os osteoblastos ( $1 \times 10^{4} /$ poço $)$ foram incubados em placas de cultura de fundo chato de 96 poços (Costar Corp., Cambridge, MA, USA) e mantidos em meio DMEM (10\% $\mathrm{SFB})$. A proliferação foi avaliada após 24 e 48 horas de cultivo.

O LPS de Escherichia coli O26:B6 (Sigma, St. Louis, MO, EUA) foi adicionado ao meio de cultura das células nas concentrações de 0,1, 1 e 10 $\mu \mathrm{g} / \mathrm{mL}^{4,5,12}$. Os grupos controle não receberam o tratamento com o LPS.

Após cada período de cultivo, foi realizada a lavagem com $200 \mu \mathrm{l}$ de PBS 1x, e adicionados $50 \mu \mathrm{l}$ de MTT $(0,5 \mu \mathrm{g} / \mathrm{ml}$ em tampão) (3-[4,5-Dimethylthiazol-2yl]-2,5-diphenyltetrazolium bromide; Thiazolyl blue SIGMA), posteriormente foi feita uma incubação de quatro horas, a $37^{\circ} \mathrm{C}$.
Terminado o tempo de incubação, a solução foi removida, sendo adicionados $100 \mu \mathrm{l}$ de isopropanol para ressuspender e solubilizar o precipitado. Por fim, realizou-se a leitura da placa com auxílio de um leitor de placas a uma absorbância de $620 \mathrm{~nm}^{14}$.

\section{Anólise dos resultados}

Para a análise dos dados, utilizaram-se média, desvio-padrão e a análise de variância (one-way ANOVA) com auxílio do software GraphPad InStat-3. Selecionou-se esse teste estatístico por se tratar de grupos não-pareados. Quando observadas diferenças estatisticamente significantes $(\mathrm{p} \leq 0.05)$, aplicava-se o pós-teste Tukey.

\section{Resultados}

Nas primeiras 24 horas de cultivo celular na presença de LPS, não houve diferença entre a proliferação celular dos grupos experimentais e do grupo controle (Figura 1).

Figura l: Valores obtidos de absorbância de acordo com os grupos experimentais, após 24 horas. Não houve diferença estatisticamente significante entre os grupos $(p>0,05)$

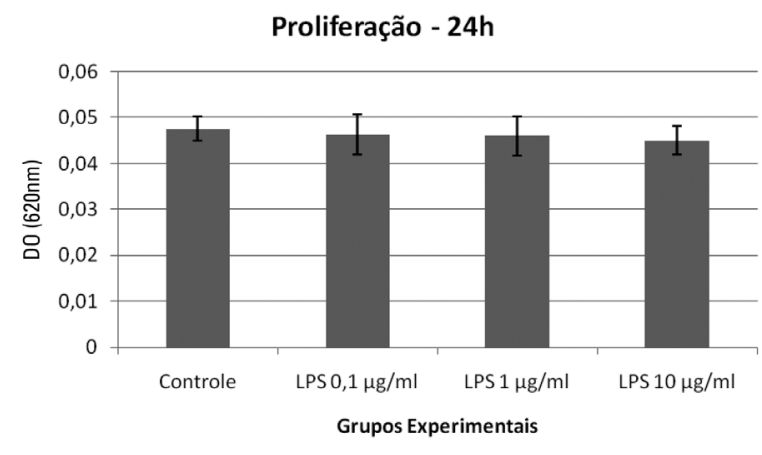

Após 48 horas de cultivo, foi possível observar que houve uma tendência de diminuição da proliferação celular no grupo tratado com LPS na concentração de $1 \mu \mathrm{g} / \mathrm{ml}$ em comparação com o controle e com todas as outras concentra- 
ções, entretanto, sem diferença estatisticamente significante (Figura 2).

Figura 2: Valores obtidos de absorbância de acordo com os grupos experimentais, após 48 horas. Diminuição da densidade ótica (DO) do grupo tratado com LPS 1 jg/ml, comparado aos demais, porém sem significância estatística $(p>0,05)$

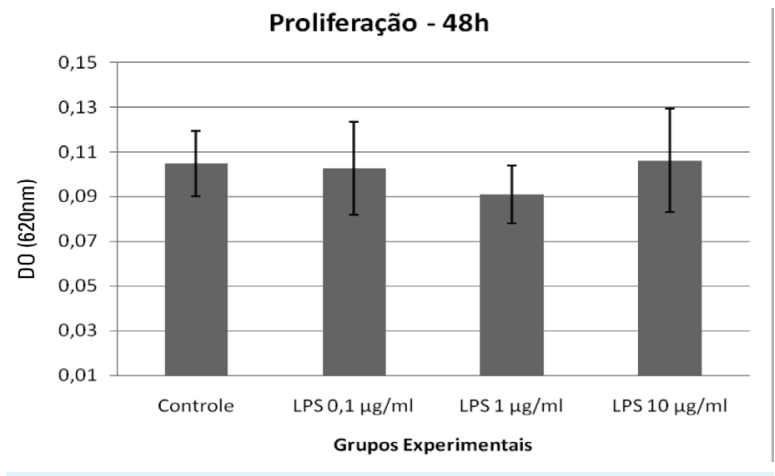

\section{Discussão}

O LPS é tido como indutor indireto de osteoclastogênese ${ }^{5,6}$. Neste estudo, utilizou-se o LPS, advindo de E. coli, por já ter sido usado em estudos anteriores com culturas de osteoblas-

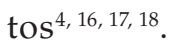

Em uma pesquisa conduzida por Shoji et al. $^{12}$, em 2006, utilizando o mesmo LPS deste estudo (E. coli 026-B6), mas avaliando a linhagem de osteoblastos Saos-2 (derivada de osteossarcoma humano), mostrou que o LPS nas concentrações de 1 e $10 \mu \mathrm{g} / \mathrm{ml}$, foi capaz de reduzir a proliferação celular, avaliada por um método metabólico, após cinco dias de cultura ${ }^{12}$. No trabalho aqui apresentado, observou-se que o efeito do LPS sobre osteoblastos OSTEO-1 pode se dar de forma muito mais precoce, já que se verificou que após um período de apenas 48 horas a concentração de $1 \mu \mathrm{g} / \mathrm{ml}$ capaz de induzir uma tendência de diminuição na proliferação. Essa diferença de resultados pode estar relacionada a diferenças na linhagem celular, ao período estudado e ao tipo de metodologia empregada.

Em 1999, Kadono et al. ${ }^{19}$, ao aplicarem diferentes concentrações de LPS de $P$. gingivalis (de zero a $100 \mathrm{ng} / \mathrm{ml}$ ), em cultura primária de osteoblastos de calvária de ratos não observaram qualquer diferença na proliferação celular, aferida por quantidade DNA celular, entre seus grupos. A diferença em relação ao nosso resultado pode ser devido a diferenças na resposta ao LPS de $P$. gingivalis, ou diferenças no método de aferição da proliferação.

Katono et al. ${ }^{17}$ observaram que células de linhagem de osteossarcoma humano não diminuíam sua proliferação, avaliada por um método metabólico, apesar da introdução do LPS de E. coli na concentração de $100 \mathrm{ng} / \mathrm{ml}$, constatando que ela era capaz apenas de interferir na diferenciação celular e na quantidade de fosfatase alcalina produzida.

A despeito dos resultados contrastantes em relação ao papel inibitório do LPS na cultura de osteoblastos, tem-se como certo o seu papel indutor da resposta inflamatório e de reabsorção óssea. Ressalte-se que, apenas pelo fato de ele ser capaz de inibir a proliferação de osteoblastos nos tecidos, ele já seria responsável pelo atraso na reparação óssea. Contudo, observando a literatura, constatou-se que o possível papel do LPS não se resume somente a interferência na proliferação, mas também na formação de osteoclastos independentemente da presença de osteoblastos ${ }^{5}$; do aumento de citocinas inflamatórias com ação fundamental no metabolismo ósseo, tais como TNF- $\alpha$, IL- 1 , IL-6, PGE2, e da matriz metaloproteinases 1, 2, 3 e 9 e osteoproteogerina ${ }^{5,6,8,9,17,18,20}$.

\section{Conclusão}

Neste estudo, mostrou-se que houve uma tendência de diminuição da proliferação de osteoblastos, em curto prazo, tratados com LPS, na concentração de $1 \mu \mathrm{g} / \mathrm{ml}$; entretanto, mais estudos são necessários, para melhor compreensão do processo de reabsorção e reparação óssea mediada por bactérias, devido a sua complexidade e presença de múltiplos mediadores envolvidos. 


\section{Referências}

1. Heymann D, Rousselle AV. gp130 Cytokine family and bone cells. Cytokine 2000;12(10):1455-68.

2. Harada S, Rodan GA. Control of osteoblast function and regulation of bone mass. Nature. 2003;423:34955 .

3. Boyle WJ, Simonet WS, Lacey DL. Osteoclast differentiation and activation. Nature 2003;423:337-42.

4. Jung WK, Park IS, Park SJ, Yea SS, Choi YH, Oh S, Park SG, Choi IW. The 15-deoxy-Delta12,14prostaglandin $\mathrm{J} 2$ inhibits LPS-stimulated AKT and NF-kappaB activation and suppresses interleukin-6 in osteoblast-like cells MC3T3E-1. Life Sci. 2009 Jul 3;85(1-2):46-53.

5. Jiang J, Zuo J, Chen SH, Holliday LS. Calcium hydroxide reduces lipopolysaccharide-stimulated osteoclast formation. Oral Surg Oral Med Oral Pathol Oral Radiol Endod. 2003;95:348-54.

6. Nair SP, Meghji S, Wilson M, Reddi K, White P, Henderson B. Bacterially induced bone destruction: mechanisms and misconceptions. Infect Immun. 1996;64:2371-80

7. Hausmann E, Raisz LG, Miller WA. Endotoxin: stimulation of bone resorption in tissue culture. Science. 1970;168:862-4.

8. Aznar C, Fitting C, Cavaillon JM. Lipopolysaccharide-induced production of cytokines by bone marrow-derived macrophages: dissociation between intracellular interleukin 1 production and interleukin 1 release. Cytokine. 1990;2:259-65.

9. Agarwal S, Piesco NP, Johns LP, Riccelli AE. Differential expression of IL-1h TNF-a, IL-6, and IL-8 in human monocytes in response to lipopolysaccharides from different microbes. J Dent Res. 1995;74:1057-65.

10. Meryon SD, Perris AD. Lipopolysaccharide-induced bone resorption is mediated by prostaglandins. Life Sciences. 1981;28:1061-5.

11. Bom-van Noorloos AA, van der Meer JW, van de Gevel JS, Schepens E, van Steenbergen TJ, Burger EH. Bacteroides gingivalis stimulates bone resorption via interleukin-1 production by mononuclear cells. The relative role for $\mathrm{B}$. gingivalis endotoxin. J Clin Periodontol. 1990;17:409-13.
12. Shoji M, Tanabe N, Mitsui N, Tanaka H, Suzuki N, Takeichi $\mathrm{O}$ et al. Lipopolysaccharide stimulates the production of prostaglandin E2 and the receptor Ep4 in osteoblasts. Life Sci. 2006 Mar 20;78(17):2012-8.

13. Deboni NCZ. Obtenção e caracterização de linhagem de células osteoblásticas [dissertação de doutorado em Patologia Bucal]. São Paulo: Faculdade de Odontologia, Universidade de São Paulo; 1995.

14. Mosmann T. Rapid colorimetric assay for cellular growth and survival: application to proliferation and cytotoxicity assays. J Immunol Methods. 1983;65(2):55-63.

15. Löster K, Horstkorte R. Enzymatic quantification of cell-matrix and cell-cell adhesion. Micron. 2000;31:41-53.

16. Choi HG, Kim JM, Kim BJ, Yoo YJ, Cha JH. Mouse strain-dependent osteoclastogenesis in response to lipopolysaccharide. J Microbiol. 2007;45(6):566-71.

17. Katono T, Kawato T, Tanabe N, Tanakab H, Suzuki N, Kitami S, Moritaa T, Motohashi M, Maeno M. Effects of nicotine and lipopolysaccharide on the expression of matrix metalloproteinases, plasminogen activators, and their inhibitors in human osteoblasts. Arch Oral Biol. 2009;54:146-55.

18. Kondo A, Koshihara Y, Togari A. Signal transduction system for interleukin-6 synthesis stimulated by lipopolysaccharide in human osteoblasts. J Interferon Cytokine Res. 2001;21:943-50.

19. Kadono H, Kido JI, Kataoka M, Yamauchi N, Nagata T. Inhibition of osteoblastic cell differentiation by lipopolysaccharide extract from Porphyromonas gingivalis. Infect Immun. 1999;67:2841-6.

20. Le XK, Laflamme C, Rouabhia M. Porphyromonas gingivalis decreases osteoblast proliferation through IL-6-RABKL/OPG and MMP-9/TIMPs pathways. Indian J Dent Res. 2009;20(2):141-9. 